\title{
THE INFLUENCE OF KAZI KWA VIJANA PROGRAMME ON RURAL DEVELOPMENT IN RONGO DISTRICT, KENYA
}

\author{
Lukes Onyango, PhD \\ Lecturer, Kenya \\ Aketch Ng'ong'a, PhD \\ Business Strategy Consultant, Kenya \\ http://doi.org/10.35409/IJBMER.2020.3189
}

\begin{abstract}
This study sought to investigate the role of youth empowerment on rural development in Rongo district. Stratified random sampling technique was used to select a sample of 100 youths, 10 community leaders, and 30 social development workers. The study used structured questionnaires targeting the youths and an interview schedule for the local community leaders to collect data. Descriptive statistics (frequency distributions and mean) were used to analyze and summarize study data while inferential statistics such as chi square were employed to test the relationship between independent and dependent variables. The study established that Jua kali, environmental conservation, HIV/AIDS prevention and financial empowerment through youth trust fund were the main activities practiced under the Kazi Kwa Vijana programme in Rongo district. There existed a significant relationship between participation level of the youth and rural development. There was a further significant relationship between accessibility of the project and rural development. The study also showed that there existed a significant relationship between the length of the programs and rural development in Rongo District. The study recommends that there is need of engaging the private sector in providing employment and training and that priority should be given to sub-projects that can be implemented rapidly using labor intensive techniques. The study also recommends that Rongo district should adopt the best practice operational features of public works program. Together with the International Labour Organization (ILO), the Government should endeavor to master the management of the implemented programs and develop a design that allows for flexibility based on demand, with possible scaling-up and scaling-down as necessary.
\end{abstract}

Keyword: Kazi Kwa Vijana Programme(KKVP), Rural Development, Rongo District, HIV/AIDS Prevention, Financial Empowerment, Jua Kali, International Labour Organization(ILO)

\section{INTRODUCTION}

\subsection{Background to the Study}

The concept of Youth could have many connotations to different people and organizations. Definitions range from those that are purely of a legal nature to those that are of a functional one. In all countries, the terms adolescent, teenager, youth all refer to young people undergoing physical, mental and cultural transition from childhood to adulthood. According to World Health 


\title{
International Journal of Business Management and Economic Review
}

\author{
Vol. 3, No. 04; 2020
}

ISSN: 2581-4664

Organization (WHO), adolescents are people age 10 to 19 and young people aged 10-24 (WHO, 2007). There are over one billion young people (aged 15-24) in the world today, which amounts to some $18 \%$ of the world's total population (WHO, 2007). Even though the term youth varies in its significance and age range from culture to culture, it may universally be defined as a transitional concept .That means youth is viewed as a very specific stage between childhood and adulthood, when people have to negotiate a complex interplay of both personal and socioeconomic changes in order to maneuver the 'transition' from dependence to independence, take effective control of their own lives and assume social commitments.

The global situation of young people today is characterized by striking paradoxes, which is in extreme disparities in terms of economic, technological, social and cultural resources which vary enormously across regions, countries, localities and population groups. Almost $85 \%$ of young people live in developing countries, with approximately 60\% in Asia alone. Despite mass urbanization, the majority live in rural areas. Young men outnumber young women (525 million versus 500 million), while 57 million young men and 96 million young women are illiterate. In developing countries, rapid changes in the social conditions of young people as a result of changing socio-economic and policy structures, and wider global change mean that they face a more precarious future than any preceding generation (Chigunta, 2002).

According to Messner and Tardiff (1986), youths are disproportionately susceptible to poverty in comparison with other age groups primarily because of the fluid nature of the challenges and opportunities they face during transition to adulthood, particularly in relation to the labour market. Efforts to support youths' healthy development and integration into the community have experienced several shifts in focus over the past few decades (Small, 2004). Historically, a primary function of youth programs was rehabilitation or containment (e.g., keeping youth off the streets). An initial shift from these risk-based preventive approaches was in the direction of fostering healthy youth development and capacity building through active community participation (Kim, 1998; Small, 2004). More recently, positive youth development approaches have been expanded to incorporate a focus on youth empowerment. Empowerment is a multilevel construct consisting of practical approaches and applications, social action processes, and individual and collective outcomes. In the broadest sense, empowerment refers to individuals, families, organizations, and communities gaining control and mastery, within the social, economic, and political contexts of their lives, in order to improve equity and quality of life (Rappaport, 1984; Rappaport, 1987; Zimmerman, 2000).

According to Small (2004), today's young generation experiences widening social gaps and faces manifold challenges: it is the young who - perhaps more so than any other social group encounter the uncertainties and risks generated by the process of economic and cultural globalization. Even though, in some parts of the world, young people are better educated than ever before, they are faced with increasing insecurity in the labour market. Those who have the opportunity to go to school are forced to study longer and longer as job opportunities become scarcer, less well-paid and less secure, delaying the age at which they become financially independent from their parents. The overall youth policy in Kenya tries to capture the multisectorial focus of the Policy. It is geared towards empowering the youths by creating an enabling 


\section{International Journal of Business Management and Economic Review}

Vol. 3, No. 04; 2020

ISSN: 2581-4664

environment and marshalling the resources necessary for undertaking programmes to fully develop youth's mental, moral, social, economic, political, cultural, spiritual and physical potential in order to improve their quality of life. In rural areas, the youths are engaged in small scale farming and semi-skilled or skilled metal works. Some are engaged in temporary employment in agro based industries while others do fishing. In local district most of the youths engage themselves in small scale farming, retailing, transport and fishing. The earnings from employment are used for subsistence or on consumption and savings are not enough to enable them to invest in viable projects which will generate high levels of income to improve the living standards and rural development in general.

The KKV programme is a nation-wide initiative which employs 200,000 - 300,000 Kenyans, primarily the youths, who are at risk of hunger and starvation. This was to enable them to earn income, to buy food and other basic items and to support their families. The KKV is intended to help meet these two critical needs, namely: Providing relief to the people at risk through gainful employment and contributing to increasing food production, particularly through better utilization of our water resources. Those employed in the KKV are engaged in manual-based small projects in their own communities. In rural areas, they build water dams and irrigation, repair borehole and access roads, clear bushes and plant trees. In urban areas, the KKV workers build and operate water kiosks, develop and implement waste management systems, and repair and maintain access roads, all to improve quality of life particularly in the slum areas.

\subsection{Statement of the Problem}

The Kazi Kwa Vijana youths programme is an initiative by the government to empower the youth to engage in productive activities and improve their social and economic status in the society. Youth empowerment programmes have been assigned to assist the youth to participate in general development in Kenya. When the youth programme is carried out as planned then the rate of crime in the community reduce, the youths start business enterprises to improve their financial status and appreciate the environment sustainability for the good of the community (GOK, 2009). The programmes are meant to be controlled and managed by the youths themselves to gain skill. However, it is paradoxical that the KKV programme has not been evaluated to ascertain its influence on development. It is on the basis of this that this study investigated the contribution of Kazi Kwa Vijana youth empowerment programmes on rural development in Rongo district.

\subsection{Research Objectives}

(1).To identify the activities carried out by the youth in Kazi Kwa Vijana programme in Rongo district

(ii).To establish the influence of the project accessibility of the youth empowerment programmes on rural development in Rongo district

(iii).To determine the relationship between the level of youth participation in the empowerment programmes and rural development in Rongo district

(iv).To establish the relationship between the length of youth empowerment programmes and rural development in Rongo district 


\section{International Journal of Business Management and Economic Review}

Vol. 3, No. 04; 2020

ISSN: 2581-4664

\section{EMPERICAL LITERATURE REVIEW}

\subsection{Theories in Youth Empowerment}

According to Pinderhughes, (1995), empowerment is a social action process that can occur at multiple levels, e.g., individual, family, organization, and community. Theorists and researchers across multiple disciplines have examined and analyzed empowerment and linked it to individual and collective health, well-being, and environments. Rocha (1997) proposed empowerment as a continuum or ladder, with Atomistic Individual Empowerment (focus on changing the individual) and Political Empowerment (focus on changing the community) as the two endpoints. Such a continuum focuses on only one dimension of empowerment-the level or subject (individual vs. collective). At the individual level, psychological empowerment focuses on individual-level capacity-building, integrating perceptions of personal control, a proactive approach to life, and a critical understanding of the sociopolitical environment. According to (Zimmerman, 1995; Zimmerman, 2000) Collective empowerment occurs within families, organizations, and communities, involving processes and structures that enhance members' skills, provide them with mutual support necessary to effect change, improve their collective well-being, and strengthen intra-Jennings et al and inter-organizational networks and linkages to improve or maintain the quality of community life.

Rissel (1994) emphasized the integrated and sociopolitical dimensions of empowerment, noting that community empowerment includes a raised level of psychological empowerment among its members, a political action component in which members have actively participated, and the achievement of some redistribution of resources or decision making favorable to the community or group in question. The common models are discussed as follows:

\subsubsection{Adolescent Empowerment Cycle}

The Adolescent Empowerment Cycle (AEC) is a model developed by Chinman and Linney (1998). The AEC is based on psychological theories of adolescent development and describes processes aimed at preventing a sense of rolelessness and enhance self-esteem. Chinman and Linney linked AEC to the developmental process of social bonding, leading youth to bond to positive institutions through action, skill development and reinforcement. Positive social bonding can prevent youth engagement in negative social activities. Given its theoretical basis, the AEC centers on three dimensions: adolescent participation in meaningful activities, such as community service, that provide opportunities for skill development and positive reinforcement and recognition from adults throughout the process. The authors argued that for adolescents experiencing a period of identity crisis and formation, participation in meaningful activity may contribute to role stability, offsetting a general lack of purpose or direction many adolescents experience.

Chinman and Linney (1998) offered the example of older high school students mentoring incoming freshmen regarding their transition to high school as an illustration of how the processes of the AEC might be realized. They noted that participation in peer mentoring 


\section{International Journal of Business Management and Economic Review}

Vol. 3, No. 04; 2020

ISSN: 2581-4664

activities could provide adolescents with meaningful roles and organizational and communication skills that will be useful in later life. Positive recognition by adults of the youth mentoring roles and activities would have beneficial implications for youths' maturing selfesteem and self-efficacy. However, the authors did not provide details about youths' roles and responsibilities nor did they describe how adults engage in this process with positive reinforcement, a critical feature of the AEC model (Rappaport, 1987).

\subsubsection{Youth Development and Empowerment Program Model}

The aim of the Youth Development and Empowerment (YD\&E) is to guide youth empowerment initiatives within the context of substance abuse prevention programs (Kim, 1998). Similar to the AEC model, the YD\&E goes beyond the prevention of risky behaviors and is based on meaningful participation of youth in community service projects. A key to the YD\&E process is the enhancement of positive social bonding and preparation for participation and involvement in the socioeconomic and public affairs of the community. The model is grounded in social control theory, social learning theory, and expectations-states theory. In their presentation and discussion of the YD\&E model (Zimmerman, 1988).

Kim, S., Crutchfield, C., Williams, C., \& Hepler, N. (1998) described the features of youth empowerment processes and specified core structural components that support these processes. The model explicitly incorporates dimensions of both individual empowerment and community engagement, or community partnership. The central tenet of YD\&E is the recognition that youth are assets and resources that should be called upon to participate in community and social affairs. However, the YD\&E process requires strong social support from caring and supportive adults who place high expectations on youth participants and reinforce achievement. The authors envisioned participation in youth-determined community service projects as meaningful opportunities for youth to learn life skills that have vocational implications, take responsibility, and demonstrate their abilities and success. The accomplishments also need to be recognized and celebrated by significant others in the community. Within the YD\&E model, the role of the adult leader is to serve as a guide and facilitator, allowing the youth leader to take on leadership responsibility for the ensuing activities.

As projects are completed, participants evaluate their efforts, determine future directions, recognize everyone's contributions, and celebrate their success. Desired youth outcomes include the development of positive relationships with both peers and adults, participation in social/public affairs, and demonstration of success in solving real community problems and issues (Kim et al., 1998).

\subsubsection{The Transactional Partnering Model}

According to Cargo, M., Grams, G.D., Ottoson, J. M., Ward, P., \& Green, L.W. (2003), a longitudinal qualitative study of a community-based youth empowerment program in Canada resulted in the development of a Transactional Partnering (TP) model. An inner-city community health promotion intervention aimed at youth engagement with local quality of life (QOL) issues 


\section{International Journal of Business Management and Economic Review}

Vol. 3, No. 04; 2020

ISSN: 2581-4664

was the context of this research project. The study examined the process of adult practitioners supporting youth participants in assessing their own QOL issues, developing action plans, and implementing solutions. In contrast to the AEC and YD\&E models, which were based on existing theories of youth development and psychology, the TP model of youth empowerment was developed as part of a qualitative research project. However, there are some similarities and overlap across these models.

In the TP model, youth empowerment is conceptualized as a mutual process of transactional partnering between adults and youth (Cargo et al., 2003). Key to this process is the role of adults in creating an empowering and welcoming environment and facilitating and enabling youth. The findings from the qualitative research described various ways in which adults enabled youth. These included ensuring youth had the skills and knowledge they needed to participate in community change. Efforts through adult facilitating, teaching, mentoring, and providing feedback. One strategy adult facilitators used was to provide youth participants with a roadmap to guide their assessment of QOL issues, develop action plans, and implement solutions. The researchers noted that over time, adults incrementally gave up responsibility for voicing, decision making, and action, making it available for youth to take. Adult practitioners apparently needed to determine the amount of support required without undermining the very autonomy enablement is intended to foster and incrementally transferred responsibility and decision making power to youth as they gained competence and confidence.

Another central tenet of the TP model is the notion of the inter-relatedness of individual and community-level empowerment outcomes. Youth are expected to experience individual outcomes incrementally through participation and success in community change efforts. These outcomes include increased self- and community-esteem, confidence, and competencies such as voicing one's opinion and leadership. Participants also achieve community-level empowerment and develop participatory competence, or the ability to work successfully with others through cooperation, compromise, and appreciation. Youth control is manifest through youth taking responsibility, voicing their opinions, making decisions, and taking action to achieve their goal. The TP model reflects the premise that exposing youth to opportunities and challenges within a safe and supportive environment, and the resulting engagement and reflection, can result in learning and empowerment (Cargo et al., 2003). In describing the context of the research from which the TP model developed, the authors did not provide descriptions of specific youth activities, projects, or organizational outcomes. However, they outlined processes that supported youth empowerment, defined as healthful adaptation of youth to confronting challenges associated with directing a youth-defined agenda (Cargo et al.2003).

The researchers observed a variety of youth outcomes, including positive self-attributions (selfesteem) and group attributions (collective esteem) in response to achieving success; expressions of increasing confidence over time; evidence of clearer understanding of the workings of local community affairs (raised consciousness); development of voice and advocacy competencies by talking with greater openness in a group of peers and adults; and increased participatory competence (e.g., cooperating, compromising, appreciating diverse viewpoints, and abandoning stereotypes). The authors argued that TP supported not only youth development (e.g., autonomy, 


\section{International Journal of Business Management and Economic Review}

Vol. 3, No. 04; 2020

ISSN: 2581-4664

identity, expansion of life chances) but also opportunities to become more socially integrated into the community.

\subsubsection{The Empowerment Education Model}

Working with community adult literacy programs in Brazil, Freire (1970), developed and applied his theories of critical social praxis. The premise of his work is that liberating and empowering education is a process that involves listening, dialogue, critical reflection, and reflective action. Freirian concepts of concretization, liberation, praxis, and empowerment education have been incorporated into various health education initiatives and models. In developing a youth empowerment model for an adolescent health program, Wallerstein, Sanchez-Merki, and Velarde (2005) linked Freirian concepts and practices with protection motivation behavior change theory.

The resulting Empowerment Education (EE) model specifically emphasizes the development of skills and knowledge that support youth efforts toward social action and change and links individual empowerment to community organizing. The authors envisioned the ultimate outcomes of the EE processes as increased self-, collective-, and political-efficacy, resulting in both self-protective individual behaviors as well as other-protective socially responsible behaviors. By fostering the development of empathy and active participation in critical analysis of societal forces within a safe group context, EE can bridge individual behavior change and group efforts for social change.

The EE model guided the development and implementation of a community health prevention program serving predominantly Native American, Hispanic, and low-income Anglo communities in New Mexico (Wallerstein, Sanchez-Merki, and Velarde, 2005). The program offered small groups of youth the opportunities to interview and interact with hospital patients and prison inmates with personal experiences related to drug, tobacco, and alcohol abuse, interpersonal violence, HIV infection, and other high-risk behaviors. The program facilitators were trained university graduate students who followed an extensive curriculum and engaged youth in a Freirian listening-dialogue-action-reflection cycle. The EE process involved story-telling, listening, and sharing of life experiences between the youth and the hospital patients and prison residents.

These personal interviews and interactions were followed by participation in group sessions of structured reflection and discussion revolving around the personal, social, medical, and legal consequences of risky behaviors, and the exploration of action. Strategies to help participants make healthier choices for themselves and their communities. Through these dialogue cycles, youth engaged in critical reflection, or concretization, analyzing the societal context for personal problems and their own role in working on the problems. Protection-motivation variables were integrated throughout the dialogue cycles.

\subsection{Empirical Studies on Youth Empowerment and Development}

A study carried out by Cook (1991) in the Republic of Canada has resulted into the development of various policies that have impacts on the youth of the country. However, it did not have an 


\section{International Journal of Business Management and Economic Review}

Vol. 3, No. 04; 2020

ISSN: 2581-4664

explicit youth policy until now. An analysis of the youth situation in Canada reveals that there are a number of major youth issues (social, economic, cultural) that need to be dealt with as part of the numerous development programmes and strategies in the country. Some of these issues constitute serious obstacles to youth development and to improving the quality of life of the population.

According to Cook (1991), youths are the potential strength of a nation; they constitute the pillar upon which a nation is built. They are full of energy, enthusiasm and dynamism. Their potentials have to be channeled to enable them to play a constructive role in the socio-economic development of the country. A national youth policy is of vital importance to empower youth to contribute to the shaping and building of the nation. It represents a declaration of the priority and directions that a country intends giving to the development of its young women and men. It is a statement outlining the vision, the values and principles that guide us, the issues that challenge us, and the initiatives, programmes and delivery mechanisms being planned and implemented to improve the socio-economic well-being of our youth. This policy therefore provides broad guidelines from which action programmes and services could be developed to facilitate meaningful involvement of youth in national development efforts that will respond to their various needs and problems (Cook, 1991). It is acknowledged that the development of young people in Kenya requires the involvement of different groups and sectors. The National Youth Policy therefore provides a means whereby these different sectors (Government, NonGovernment, Community, and Private) as well as young people themselves, can work together to achieve common goals.

A study by Jacobs, Wertlieb, and Lerner (2003), on key issues on youth empowerment in Development Plans, Policies and Programmes suggested that previous development plans have not addressed youth issues specifically but implicit in their various strategies one finds some aspects of the youth concerns considered such as in the areas of human resources development and employment. For example, the Three Year Medium- term Development Plan 1998-2000 seeks to address the following issues relevant to youth: inequitable land distribution and ownership; inadequate human resource base and relevant skills; and insufficient infrastructure development. Priority policy objectives mentioned in the plan include: creation of more employment opportunities; provision of infrastructure through increased capital budget and private sector participation; improvement in the provision of education and health services; and promotion of small and medium-scale enterprises.

\subsubsection{Activities carried out by the Kazi kwa vijana youth programme}

According to Government of Kenya (2009) the Kazi kwa vijana initiative is supposed to carry out the activities of opening up trenches in various to improve drainage systems and clean the environment. The programme also takes up the tasks of training the youth on entrepreneur skills and saving incomes to start profit making businesses. The kazi kwa vijana initiative is meant to assist the youth preoccupy themselves in activities which will enable them to reduce anti-social activities which are counterproductive to the society. 


\section{International Journal of Business Management and Economic Review}

Vol. 3, No. 04; 2020

ISSN: 2581-4664

\subsubsection{Influence of accessibility of youth empowerment programmes on rural development}

Even where youth empowerment programs exist, many youth do not have sufficient access to them (Camino, 2002.) In some cases, this is because of scarce resources, resulting in limited program size. In other cases, generic problems of publicity and outreach limit access. The large distances between communities and fragmented social networks in an Rongo District present a much bigger challenge than is the case in many urban areas. Some communities are beginning to create collaborative networks to address the fragmentation problems.

In their report, (Camino, 2002) illustrated, the provision of and access to empowerment opportunities in the Central Valley in USA was insufficient relative to the interests and aspirations of the region's young people. At the same time, there were examples of innovative, effective programs that offer genuine and substantive empowerment roles for youth. These promising practices deserve increased investment to deepen their effect and to expand their reach to the region's underserved populations.

Existing empowerment opportunities tend to involve youth with prior advantages and are less accessible to underserved youth (e.g., recent immigrants, poor youth, youth of color) (Ginwright, Shawn and Taj James, 2003). According to Ginwright et al (2003), opportunities for, and access to, empowerment activities are particularly limited in the rural areas. Lack of resources such as program space, funding and relationships with colleagues and allies limit organizations' capacity to develop high-quality youth empowerment programs. In particular, youth action programs tend to be concentrated in urban areas, restricting the majority of rural youth's access to these programs. For example of 19 youth action programs surveyed in their study, only 6 were in rural areas, with just two in small rural communities.

\subsubsection{Influence of level of youth participation in the empowerment programmes on rural development}

According to World Bank (1994), socio-economic factors can hinder or enhance youth empowerment in development programmes at all levels. They affect youth participation in agricultural activities, and information and communication technology. Socio-economic factors determine the extent to which youths can partake in developing their communities through cultural activities. They constitute the framework that determines the general outcome of youth behaviours and their influence on the society at large (World Bank, 1994).

Most of the socio-economic factors that affect the empowerment of youths in development programmes are infrastructural facilities, working capital, and standard of education, policy reversals, and systems of taxation, systematic corruption, and violence. They also include mass media, state of the national economy, nature of public institutions, cultural and historical background, gender perceptions/values, family background, social networks and supports, and community structures (Chigunta, 2002). While appreciating the influence of socioeconomic factors, this study will identify the specific factors that impact on the youth empowerment and rural development.

From the social work perspective, the empowerment of the youth for community development 


\section{International Journal of Business Management and Economic Review}

Vol. 3, No. 04; 2020

ISSN: 2581-4664

approach enables practitioners to investigate reality with the poor that is the working poor, the physically and mentally challenged, and the youth, to help them confront the obstacle imposed by class, race, and differences in order to reduce crime in the society (Akinyemi, 1990). Thus, the synthesis of a wide range of theories and skills is needed for effective integration, actively involving the target population for empowerment at all levels of decision making, in this context, the youth. This study therefore sought to apply the theories of youth empowerment to establish the linkages between youth empowerment and rural development.

\subsubsection{Influence of length of youth empowerment programmes on rural development}

According to the Government of Kenya (2010) when implementing youth empowerment projects, priority is normally given to sub-projects that can be implemented rapidly using labor intensive techniques such as road maintenance, small-scale water supply and sanitation, water harvesting, afforestation, and waste collection. The implication of this is that youth will tend to actively participate in projects that take a short period of time as compared to those that take longer. This is so given the relatively simple and mostly manual nature of most KKV work (with the exception of some drilling in the case of the sewage pipeline laying).

\subsubsection{Youth Empowerment in rural development}

\subsubsection{Indicators of Youth Empowerment}

According to Ray (1992), youth empowerment involves equipping the youth with all kinds of empowerment to pursue high levels of social, economic, political and technological progress in the society. The indicators of youth empowerment is manifested in the ability to be financially able to start their own businesses, be self-employed, seek leadership in the society, provide employment to the others, contribute in social development, participate in maintaining and sustaining the environment and finance their career progression and development through training.

\subsubsection{Levels of youth empowerment}

In the same vein, Schueman and Kobrin (1986), state that the socio-economic levels of young people determine the prospects of empowering or creating additional livelihood opportunities for them. Consequently, this will determine the level of their participation in community development. To develop and empower youths for community development participation, the government and other stakeholders (NGO's) must coordinate and organize youth empowerment programmes aimed at integrating them (the youths) into the crucial task of community development. Socio-economic factors are external forces within the society which determine the outcome of people's lives (World Bank, 1994). They can be risk factors which increase the likelihood of experiencing negative outcomes, for example high crime and violence neighbourhoods (Sampson and Lauristen,1993); and they can be protective factors which increase the likelihood of experiencing positive outcomes, for example caring family (Blum, 2003).

According to Miezek et al (1993), communities with very high rates of youth violence are places in which there are high concentrations of criminogenic commodities. Both alcohol and drug use 


\section{International Journal of Business Management and Economic Review}

Vol. 3, No. 04; 2020

ISSN: 2581-4664

are highly correlated with violent crime at the situational level of analysis and gun use in crime generally causes greater risk of homicide. Another evidence suggests that high crime communities appear to have very high concentrations of locations selling alcohol and drugs. Youth suffering from poverty have higher rate of juvenile delinquency, crime records and their proximity to drug and alcohol abuse is equally high. A lot of them who are neither having education (formal or informal) nor working, due to lack of fund or lack of adequate skills, get involved in various criminal activities, like stealing, pick- pocketing, raping, robbery, kidnapping, ritual killing etc. They usually live in bad neighborhoods where positive role models are either non- existent or out of reach.

\subsubsection{Effects of youth Programmes on Youth Empowerment}

A study carried out in Zimbabwe by Ray (1992), suggested that youth programmes should empower the youth through Education and Vocational Skills Training. Ray (1992) further asserts the youth programmes should strengthen community based support programme for children in especially difficult circumstances while advocating for establishment of participatory parent education programmes related to youth problems and parent-child communication. The programmes should further identify and undertake priority research studies that will advance youth development; Establish adequate and valid linkages between education and employment; Strengthen civic education programmes for the youth; Promote industrial exposure to students; and encourage participatory partnership between the educators, students and the community and ensure that development strategies and programmes incorporate youth employment concerns and encourage and develop specific youth-oriented programmes that improve the skills, productivity and experiences of young people. The youth empowerment should also: establish a youth fund and encourage access to capital by the youth; Ensure fair distribution of land for the youth who have reached legal age of majority and provide appropriate training for its utilization; Encourage youth participation in land distribution and conservation; Promote career guidance and counselling in both public and private sectors, to assist young people more efficiently in finding employment (Ray, 1992).

According to Roth, Brooks-Gunn, Murray, and Foster, (1998), youth empowerment is the creation of an enabling environment for the youth to have the freedom to choose, to participate in and take decisions in matters affecting them and be ready to accept the consequences of their decisions. Empowerment enables the youth to be active participants in both the process and product of development. The following strategies will be applied. Involve young people during the planning, implementation, monitoring and evaluation of youth programmes. Further, the programmes should empower teachers, parents, students, out of school youth and health service providers with necessary information and skills regarding youth, sexuality and sexual education through training workshops, meetings and distribution of information, education and communication (IEC) materials (Roth, Brooks-Gunn, Murray, and Foster, 1998).

A study in Nigeria on Mobilization of Resources, Monitoring and Evaluation by Akinyemi, (1990) maintains that the attainment of the goals and objectives of this Policy hinges on the effective mobilization of resources, for the implementation of policy related programmes. It is envisaged that these resources will come from various sources. The Policy requires Government 


\section{International Journal of Business Management and Economic Review}

Vol. 3, No. 04; 2020

ISSN: 2581-4664

to provide adequate resources for its implementation. Government shall mobilize adequate human and material resources to the programme for implementing the Policy. Government shall also mobilize community support, as well as support in cash and kind from private organizations in the country. External support shall also be mobilized, including technical and financial inputs, to ensure the successful implementation of the Youth Policy. Monitoring and evaluation are the means of assessing the implementation of the goals, objectives and strategies of the Youth Policy. Timely and periodic monitoring and evaluation shall be undertaken by appointed authority.

A study carried out in Nigeria on Youth Empowerment as a Strategy for Reducing Crime in the Society by Akinyemi (1990), showed that young people account for a large percentage of Nigeria's population figure, representing an important and dynamic force in the Nigerian society. However, young people face many challenges in the Nigerian society, such as high rate of poverty and unemployment, illiteracy, lack of access to information, and essential welfare services, that are manifested in young people's diminished hopes for the future. Some of the highest rates of violence, crime and high risk sexual behaviours of any age group are seen in the youth population, leading many to label the youths as a source of society's problems rather than its potentials (Akinyemi, 1990).

According to Reiss (1988) states that in recent years, almost all governments of countries of the world, including advanced countries have sought new approaches to harness the potential of young people and address the problems facing them. The concept of youth empowerment has gained increasing attention. Youth empowerment means involving young people in decision making processes on issues that affect them, as well as entrusting them with the knowledge and skills necessary for them to effectively and meaningfully participate

Youth empowerment in any development is imperative not only for national development but also because the transitional period from childhood to adulthood is unquestionably a challenge for many youths (Ojikutu, 1998). There are serious social and economic consequences associated with not addressing the minority group of youths who are at the risk of negative circumstances not only for the youth themselves and their families, but also for society at large. If the potential of these youths are not profitably harnessed and marshalled towards development, there is bound to be trouble (Ojikutu, 1998). This implies that all stakeholders in youth empowerment and development, including governments, Non-Government Organizations (NGOs), religious organizations, parents, guardians, and elders have the responsibility to empower youths around them in order to jointly realize the national objective of socio-economic transformation of communities (Oladele, 2003). This study seeks to investigate the role of stakeholders such as government and other development agencies in youth empowerment and rural development.

According to World Bank, (1994) a committed and determined effort is required on the part of all stakeholders in order to help youths achieve their potentiality and make them appropriate partners in the task of community and national development. However, the ability of any stakeholder to empower youths depends on the nature of the socio-political and economic environment prevalent in the state. They can impose serious constraints in terms of meeting the 


\section{International Journal of Business Management and Economic Review}

Vol. 3, No. 04; 2020

ISSN: 2581-4664

needs and aspirations of the youths According to Chigunta (2002), unless the crises in socioeconomic factors, like employment, education, and other institutions, are addressed by the government, the crisis facing contemporary African youths and the communities where they live will remain unresolved and possibly worsen. In view of these observations, this study will further interrogate the social, political and economic environment which influences youth empowerment and rural development.

\subsection{Conceptual Framework}

Youth Programmes (Kazi Kwa Vijana)

Independent Variables

\begin{tabular}{|c|c|}
\hline $\begin{array}{l}\text { Youth Activities } \\
\text { Business enterprise programmes } \\
\text { - Social interaction programmes } \\
\text { - Capacity building programmes } \\
\text { - Youth development and }\end{array}$ & \\
\hline $\begin{array}{l}\text { Level of youth participation } \\
\text { - Active } \\
\text { - Passive }\end{array}$ & Dependent variable \\
\hline $\begin{array}{l}\frac{\text { Location of youth }}{\text { empowerment programme }} \\
\text { - Easily accessible } \\
\text { Length of the empowerment }\end{array}$ & $\begin{array}{l}\quad \text { Rural Development } \\
\text {-Economic development } \\
\text {-Socio-cultural development } \\
\text {-Technological development } \\
\text {-Political development }\end{array}$ \\
\hline $\begin{array}{l}\text { - Long term } \\
\text { - Medium term } \\
\text { - Short term }\end{array}$ & $\begin{array}{l}\text { Intervening Variables } \\
\text { - Political environment } \\
\text { - Leadership and Governance } \\
\text { - Financial resources } \\
\text { - Capacity building }\end{array}$ \\
\hline
\end{tabular}

Figure 1. The Relationship between Youth Programmes and Rural Development

\section{RESEARCH METHODOLOGY}

The research design employed a combination of exploratory and descriptive research designs. The exploratory design in this study was employed in order to explore the needs and contributions of the youth in rural development. The descriptive research design was chosen because the study involved investigation of youth empowerment programmes on rural 


\section{International Journal of Business Management and Economic Review}

Vol. 3, No. 04; 2020

ISSN: 2581-4664

development, and required determining the opinion of a group of people towards the particular issue of youth empowerment programmes and rural development. The target population for this study included all youths currently involved with youth empowerment programmes especially kazi kwa vijana in the Rongo District. In this regard, the study targeted members of the registered youth groups operating within the study area. There was an estimated 3,000 registered youth groups in the study area (Ministry of Youths and Sports, Rongo District, 2011). With an average of $70 \%$ (18) youthful members (aged between 18 and 35 years) in each youth group, there are a total of 54,000 youthful members in the study area. In addition, the study targeted the community leaders and development workers in the study area.

There was an estimated 3,000 registered youth groups in Rongo District. With an average of 18 youthful members in each youth group, there are a total of 54,000 youthful members in the study area. In order to obtain a representative sample, a formula by Israel (1992) was used.

The formula according to Israel (1992) is shown in the equation 1 below:-

$$
\mathrm{n}=\frac{\mathrm{N}}{1+\mathrm{N}(\mathbf{e})^{2}}
$$

Where $e$ is the desired precision (e.g., 0.1 for $90 \%$ confidence level). For example, the estimated target population of youthful members in Rongo district is 54,000, implying that $n=99$ as derived from equation 2 :

$$
\begin{aligned}
& n= \\
& 1+54,000(0.1)^{2}
\end{aligned}
$$$$
=
$$

For the purposes of this study, a sample of 100 youths, 10 community leaders, and 30 social development workers was used. This sample size of 140 respondents was selected since as noted by Fraenkel \& Wallen (2001, p.118), for descriptive studies a sample with minimum number of 100 is essential. A questionnaire targeting the youths was used. The questionnaire collected relevant information including youth empowerment and rural development for the survey. A structured interview schedule was employed to seek the views of the local community leaders in Rongo district. This tool was useful in seeking information that could not be known to the youth. To check for the reliability of the study instruments, the instruments were pre-tested through a pilot study which was carried out on a sample of 30 subjects drawn from the neighbouring Migori district. Split half technique was used in pretesting. Pre-testing of the data collection instrument is a critical component of minimizing measurement errors in a survey research (Mangione, 1995). This process helped determine internal consistency of the instruments. Cronbach Alpha was used to provide reliability estimates for the instruments. The items were considered reliable since they yielded a reliability coefficient of 0.84 for the questionnaires and 0.72 for the interview schedules. To determine the validity of the instruments the researcher requested the supervisors to examine the instruments for content, and make suggestions and comments which were used as a basis for modification.

The youth questionnaire was pre-coded according to themes or constructs that have an impact on youth programmes and rural development. Pre-coding helped facilitate data entry and 


\section{International Journal of Business Management and Economic Review}

Vol. 3, No. 04; 2020

ISSN: 2581-4664

verification later and when the data needed to be collected and collated. After the data had been collected field inventory data for each objective/study population was reviewed. The data was then sorted, coded and then analyzed using the Statistical Package for Social Science (SPSS version 15.0). Data was described using frequency distributions, figures and means. Data was summarized for easy analysis using Cross-tabulations in relation to the objectives and graphic displays. In the case of qualitative data, narratives were used. Paired observations were analyzed using the chi-square test of independence.

\section{RESULTS AND DISCUSSION}

Out of the 140 instruments that were filled, 138 were accepted for analysis representing a response rate of $98.57 \%$ which is statistically accepted.

\subsection{Activities carried out by the youth in the Kazi Kwa Vijana program in Rongo District}

This study set out to establish the various activities that the youth were involved in the youth empowerment programmes and rural development in Rongo District. In this regard, the study sought to collect the respondents' views on youth empowerment programmes addressing crosscutting issues, business enterprise activities, social interactions activities and capacity-building activities in the study area.

\subsubsection{Youth Empowerment Programmes Addressing Cross-Cutting Issues}

Respondents were required to indicate the extent to which they were involved in addressing cross cutting issues as part of the various activities they carried out in the youth empowerment program. Table 1 presents the findings.

Table 1: Youth Empowerment Programmes Addressing Cross-Cutting Issues

\begin{tabular}{|c|c|c|c|c|c|}
\hline \multirow[t]{2}{*}{ Activity } & \multicolumn{5}{|c|}{ Percentage Responses (\%) } \\
\hline & Very High & High & Moderate & Low & $\begin{array}{l}\text { Very } \\
\text { Low }\end{array}$ \\
\hline HIV/AIDS management & $33(23.9 \%)$ & $32(23.2 \%)$ & $56(40.6 \%)$ & $8(5.8 \%)$ & $9(6.5 \%)$ \\
\hline $\begin{array}{l}\text { Drugs and substance } \\
\text { abuse }\end{array}$ & $9(6.5 \%)$ & $32(23.2 \%)$ & $80(58 \%)$ & $17(12.3 \%)$ & $0(0 \%)$ \\
\hline Gender mainstreaming & $26(18.8 \%)$ & $40(29 \%)$ & $39(28.3 \%)$ & $33(23.9 \%)$ & $0(0 \%)$ \\
\hline Youth rehabilitation & $17(12.3 \%)$ & $72(52.2 \%)$ & $7(5.1 \%)$ & $34(24.6 \%)$ & $8(5.8 \%)$ \\
\hline Culture change & $50(36.2 \%)$ & $24(17.4 \%)$ & $49(35.5 \%)$ & $15(10.9 \%$ & $0(0 \%)$ \\
\hline
\end{tabular}

Study findings on HIV/AIDS management in indicate that $29.9 \% \%$ of respondents were involved to a very high extent, $23.2 \%$ to a high extent, $40.6 \%$ reported to a moderate extent, $5.5 \%$ to a low extent and $6.5 \%$ of respondents reported generally a very low extent. On the basis of drugs and substance abuse, majority (58\%) agreed that they were involved in drug and substance abuse control to a moderate extent.

With regard to gender mainstreaming, study findings indicate that only $18.8 \%$ of respondents 


\section{International Journal of Business Management and Economic Review}

Vol. 3, No. 04; 2020

ISSN: 2581-4664

reported generally very high, $29 \%$ reported high, $28.3 \%$ reported moderate whereas $23.9 \%$ of respondents reported generally low. Study findings also reveal that majority $(52.2 \%)$ of the youth were to a high extent involved in youth rehabilitation. Finally, study findings also show that $36.2 \%$ to a very high extent were involved in culture change initiatives, $17.4 \%$ were to a high extent involved, $35.5 \%$ were to a moderate extent and $10.9 \%$ were to a low extent involved in culture change initiatives. These findings imply that the youth empowerment programmes addressing cross-cutting that achieved significant impact including, Culture change, Youth rehabilitation and HIV and AIDS management and control.

\subsubsection{Aspects of Business Enterprise in Youth Empowerment Programmes}

Respondents were required to indicate the extent to which they were involved in addressing business enterprise issues as part of the various activities they carried out in the youth empowerment program. Table 2 presents the findings.

Table 2: Aspects of Business Enterprise in Youth Empowerment Programmes

\begin{tabular}{|c|c|c|c|c|c|}
\hline \multirow[t]{2}{*}{ Activity } & \multicolumn{5}{|c|}{ Percentage Responses (\%) } \\
\hline & Very High & High & Moderate & Low & Very Low \\
\hline $\begin{array}{l}\text { Funding of the informal } \\
\text { sector }\end{array}$ & & $41(29$. & & $40(29 \%)$ & $9(6.5 \%)$ \\
\hline $\begin{array}{l}\text { Research } \\
\text { development }\end{array}$ & $0(0 \%)$ & $41(29.7 \%)$ & $65(47.1 \%)$ & $24(17.4 \%)$ & $8(5.8 \%)$ \\
\hline Proposal development & $0(0 \%)$ & $40(29 \%)$ & $73(52$. & $25(18.1 \%)$ & $0(0 \%)$ \\
\hline $\begin{array}{l}\text { Project appraisal } \\
\text { Product design }\end{array}$ & $0(0 \%)$ & $\begin{array}{l}42(30.4 \%) \\
24(17.4 \%)\end{array}$ & $\begin{array}{l}41(29.7 \%) \\
72(52.2 \%)\end{array}$ & $8(5.8 \%)$ & $\begin{array}{l}16(11.6 \%) \\
34(24.6 \%)\end{array}$ \\
\hline
\end{tabular}

According to Table 2, 5.8\% of respondents were involved to a very high extent in funding of the informal business, $29.7 \%$ to a high extent, $29 \%$ reported to a moderate extent, another $29 \%$ to a low extent and $6.5 \%$ of respondents reported generally a very low extent participation in funding of the informal sector. On the basis of research and development, majority (47.1\%) agreed that they were involved in research and development to a moderate extent, majority $(52.9 \%)$ still agreed that they were involved in proposal development to a moderate extent. On the basis of project appraisals, $5.8 \% \%$ of respondents were involved to a very high extent, $30.4 \%$ to a high extent, $29.7 \%$ reported to a moderate extent, $22.5 \%$ to a low extent and $11.6 \%$ of respondents reported generally a very low extent participation in project appraisals. Majority $(52.2 \%)$ further agreed that they were involved in product design to a moderate extent. In general, when it came to aspects of business enterprise, majority of the respondents were to a moderate extent participating in this activity. Lack of full commitment and participation in enterprise activity may in turn result in most of the enterprises started by the youth collapsing due to lack of technical skills and poor management skills, hence not achieving the indented goals.

\subsubsection{Aspects of Social Interaction in Youth Empowerment Programmes}




\section{International Journal of Business Management and Economic Review}

Vol. 3, No. 04; 2020

ISSN: 2581-4664

Respondents were required to indicate the extent to which they were involved in addressing social interaction issues as part of the various activities they carried out in the youth empowerment program. Table 3 presents the findings.

Table 3: Aspects of Social Interaction in Youth Empowerment Programmes

\begin{tabular}{|llllll|}
\hline Activity & \multicolumn{3}{l}{ Percentage Responses (\%) } & & \multirow{2}{*}{ Very } \\
& High & & Moderate & Low & Very Low \\
\hline Sakata ball & $33(23.9 \%)$ & $34(24.6 \%)$ & $55(39.9 \%)$ & $16(11.6 \%)$ & $0(0 \%)$ \\
Cultural activities & $16(11.6 \%)$ & $50(36.2 \%)$ & $48(34.8 \%)$ & $24(17.4 \%)$ & $0(0 \%)$ \\
Christian fellowship & $49(35.5 \%)$ & $54(39.1 \%)$ & $26(18.8 \%)$ & $9(6.5 \%)$ & $0(0 \%)$ \\
$\begin{array}{l}\text { Domestic violence } \\
\text { sensitization }\end{array}$ & $17(12.3 \%)$ & $17(12.3 \%)$ & $25(18.1 \%)$ & $54(39.1 \%)$ & $25(18.1 \%)$ \\
Youth interaction & $47(34.1 \%)$ & $56(40.6 \%)$ & $9(6.5 \%)$ & $17(12.3 \%)$ & $9(6.5 \%)$ \\
\hline
\end{tabular}

Based on the study findings in Table 3, 23.9\% of respondents were involved to a very high extent in sakata ball, $24.6 \%$ to a high extent, $39.9 \%$ reported to a moderate extent, $11.6 \%$ to a low extent and $0 \%$ of respondents reported generally a very low extent participation sakata ball. On the basis of cultural activities, majority (36.2\%) agreed that they were involved in cultural activities to a high extent, majority (39.1\%) agreed that they were involved in Christian fellowship to a high extent. It was further established that majority (39.1\%) of the youth did not practice domestic violence sensitization. However it was noted that majority (40.6\%) of the respondents involved in youth interaction activities to a high extent. Participation of the youth in such activities is meant to assist the youth preoccupy themselves in activities which will enable them to reduce anti-social activities which are counter-productive to the society.

\subsubsection{Aspects of Capacity Building in Youth Empowerment Programmes}

Respondents were required to indicate the extent to which they were involved in addressing capacity building issues as part of the various activities they carried out in the youth empowerment program. Table 4 presents the findings.

Table 4: Aspects of Capacity Building in Youth Empowerment Programmes

\begin{tabular}{|c|c|c|c|c|c|}
\hline \multirow{2}{*}{ Activity } & \multicolumn{5}{|c|}{ Percentage Responses (\%) } \\
\hline & $\begin{array}{l}\text { Very } \\
\text { High }\end{array}$ & High & Moderate & Low & Very Low \\
\hline Entrepreneurial skills & $17(12.3 \%)$ & $57(41.3 \%)$ & $31(22.5 \%)$ & $25(18.1 \%)$ & $8(5.8 \%)$ \\
\hline Management skills & $8(5.8 \%)$ & $16(11.6 \%)$ & $57(41.3 \%)$ & $40(29 \%)$ & $17(12.3 \%)$ \\
\hline Marketing skills & $8(5.8 \%)$ & $33(23.9 \%)$ & $74(53.6 \%)$ & $15(10.9 \%)$ & $8(5.8 \%)$ \\
\hline Leadership skills & $17(12.3 \%)$ & $8(5.8$ & $96(6$ & 17( & $0(0 \%)$ \\
\hline $\begin{array}{l}\text { Sensitization of the } \\
\text { human rights }\end{array}$ & $25(18.1 \%)$ & $71(51.4 \%)$ & $33(23.9 \%)$ & $9(6.5 \%)$ & $0(0 \%)$ \\
\hline
\end{tabular}




\section{International Journal of Business Management and Economic Review}

Vol. 3, No. 04; 2020

ISSN: 2581-4664

Table 4 shows the level of capacity building programmes practiced in Rongo district. Majority (41.3\%) agreed that they were involved in entrepreneurial skills to a high extent, to a moderate extent $(41.3 \%)$ in management skills, to a moderate extent $(69.6 \%)$ in leadership skills and to a high extent $(51.4 \%)$ in sensitization of the human rights.

\subsection{Project Accessibility of Youth Empowerment Programmes and Rural Development}

This study set out to determine the influence of project accessibility of youth empowerment programmes and rural development in Rongo district. In this regard, the study sought to collect the respondents' views on aspects of location of youth activities and determine its influence on levels of rural development.

\subsubsection{Location of Youth Empowerment Programmes in Rongo District}

Respondents were requested to describe the accessibility of various youth empowerment programs in Rongo District. Findings are shown in table 5.

Table 5: Accessibility of Youth Empowerment Programmes

\begin{tabular}{|lll|}
\hline Accessibility & Frequency & Percentage \\
\hline Easily accessible & 121 & 87.7 \\
Not easily accessible & 17 & 12.3 \\
\hline Total & $\mathbf{1 3 8}$ & $\mathbf{1 0 0 . 0}$ \\
\hline
\end{tabular}

According to Table 5, 87.7\% of the respondents indicated that the programs were easily accessible while $12.3 \%$ indicated that the programs were not easily accessible.

\subsubsection{Relationship between Location of Youth Empowerment Programs and Rural Development in Rongo District}

The study sought to establish the relationship between the accessibility of the projects and rural development. Tables 5 and 6 show the findings.

Table 6: Cross Tabulation of Accessibility of Youth Empowerment Programmes

\begin{tabular}{|l|l|l|l|l|l|}
\hline \multicolumn{2}{|l|}{} & \multicolumn{2}{|l|}{ Level of Rural Development } & \multirow{2}{*}{ Total } \\
\cline { 3 - 5 } & & $\begin{array}{l}\text { Count } \\
\text { Developed }\end{array}$ & Underdeveloped & 121 \\
\hline $\begin{array}{l}\text { Description } \\
\text { of } \\
\text { accessibility } \\
\text { of youth } \\
\text { empowerment } \\
\text { programs } \\
\text { location }\end{array}$ & $\begin{array}{l}\text { Easily } \\
\text { accessible }\end{array}$ & $\begin{array}{l}\text { \% } \\
\text { description of } \\
\text { accessibility } \\
\text { of youth } \\
\text { empowerment } \\
\text { programs }\end{array}$ & $47.1 \%$ & $54.9 \%$ & $100.0 \%$ \\
\hline
\end{tabular}


Vol. 3, No. 04; 2020

ISSN: 2581-4664

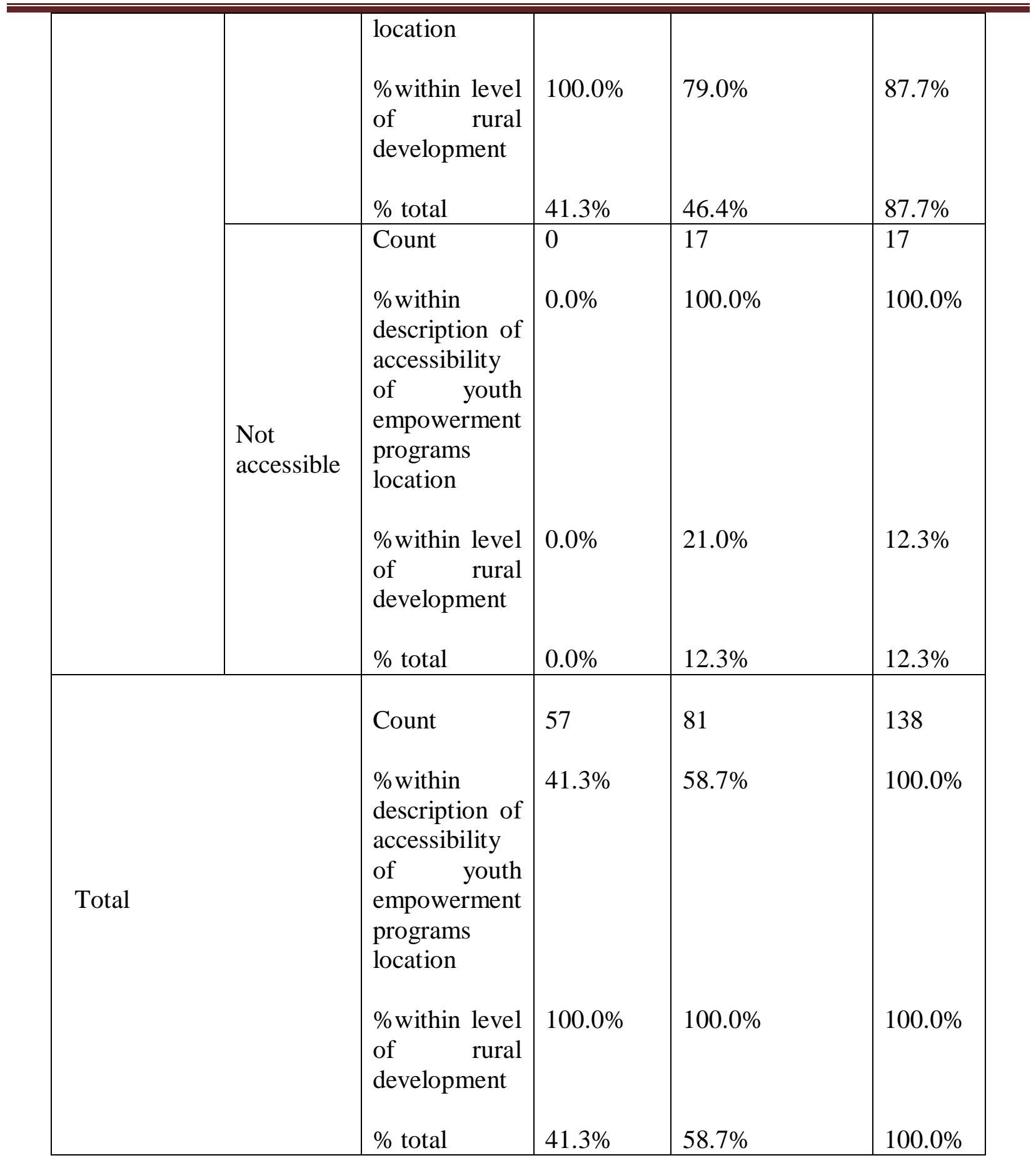




\section{International Journal of Business Management and Economic Review}

Vol. 3, No. 04; 2020

ISSN: 2581-4664

Table 6 shows that $87.7 \%$ of the respondents indicated that youth empowerment programs were easily accessible while $12.3 \%$ claimed that the programs were not easily accessible. Out of those who claimed that the programs were accessible, $47.1 \%$ indicated that their rural areas were developed while $0.0 \%$ of those who indicated that the programs were inaccessible claimed that their rural areas were developed. This implies rural development was affected by accessibility of the youth empowerment programs. This is further confirmed by the Chi square test results shown in table 7.

Table 7: Chi-Square Tests (program accessibility)

\begin{tabular}{|llll|}
\hline & Value & df & Asymp. Sig. (2-sided) \\
\hline Pearson Chi-Square & $13.644(\mathrm{~b})$ & 1 & .000 \\
Continuity Correction(a) & 11.770 & 1 & .001 \\
Likelihood Ratio & 19.777 & 1 & .000 \\
Fisher's Exact Test & & & .000 \\
Linear-by-Linear Association & 13.545 & 1 & .000 \\
\hline N of Valid Cases & $\mathbf{1 3 8}$ & & \\
\hline
\end{tabular}

A Chi-square test was done on the frequencies to establish whether a statistically significant difference existed between respondents who had easy access to youth empowerment programs and those who had no easy access to the programs. The computed Chi square value of 13.644 was significant with $\mathrm{p}=0.000<0.05$ at $5 \%$ level of significance and with 1 degree of freedom. This implies that there was a significant difference in rural development, between youth who had easy access to empowerment programs and those who had no easy access to the programs. This means that there was a significant relationship between program accessibility and rural development.

4.3 Influence of Level of Youth Participation in Youth Empowerment Programmes on Rural Development

This study set out to determine the influence of level of youth participation in youth empowerment programmes on rural development in Rongo district. In this regard, the study sought to collect the respondents' views on level of participation of youth in Kazi Kwa Vijana programmes and determine its effect on levels of rural development.

\subsubsection{Level of participation in Youth Empowerment Programmes in Rongo District}

Respondents were required to indicate the level of participation in the youth empowerment programs in Rongo District. Table 8 presents the findings.

Table 8: Level of Participation in Youth Empowerment Programmes

\begin{tabular}{|lcc|}
\hline Participation & Frequency & \multicolumn{2}{c|}{ Percentage } \\
\hline Active & 96 & 69.6 \\
Passive & 42 & 30.4 \\
\hline Total & $\mathbf{1 3 8}$ & $\mathbf{1 0 0 . 0}$ \\
\hline
\end{tabular}


Vol. 3, No. 04; 2020

ISSN: 2581-4664

Study findings in Table 8 reveal that $69.6 \%$ of youth were actively involved in the participation in the youth empowerment programmes while $30.4 \%$ were passively involved in the participation in youth empowerment programmes. It is apparent that the passive participation could be attributed to accessibility issues of youth empowerment programs.

\subsubsection{Relationship between Level of Participation in Youth Empowerment Programs and Rural Development}

The study sought to establish the relationship between the level of youth participation in the youth empowerment programs and rural development. Tables 8 and 9 show the findings.

Table 9: Cross Tabulation of Level of Youth Participation in the Empowerment Programmes

\begin{tabular}{|c|c|c|c|c|c|}
\hline & \multicolumn{2}{|c|}{ Level of Rural Development } & \multirow{2}{*}{ Total } \\
\hline & & & Developed & $\begin{array}{l}\text { Underdevelope } \\
\mathrm{d}\end{array}$ & \\
\hline \multirow{7}{*}{$\begin{array}{l}\text { Description } \\
\text { of } \\
\text { accessibilit } \\
\text { y of youth } \\
\text { empowerm } \\
\text { ent } \\
\text { programs } \\
\text { location }\end{array}$} & \multirow{4}{*}{ Active } & & 48 & 48 & 96 \\
\hline & & $\begin{array}{l}\text { \%within } \\
\text { description } \\
\text { of } \\
\text { accessibility } \\
\text { of youth } \\
\text { empowermen } \\
\text { t programs } \\
\text { location }\end{array}$ & $50.0 \%$ & $50.0 \%$ & $100.0 \%$ \\
\hline & & $\begin{array}{l}\text { \%within } \\
\text { level of rural } \\
\text { development }\end{array}$ & $84.2 \%$ & $59.3 \%$ & $69.6 \%$ \\
\hline & & $\%$ total & $34.8 \%$ & $34.8 \%$ & $69.6 \%$ \\
\hline & \multirow{3}{*}{ Passive } & Count & 9 & 33 & 42 \\
\hline & & $\begin{array}{l}\text { \%within } \\
\text { description } \\
\text { of } \\
\text { accessibility } \\
\text { of youth } \\
\text { empowermen } \\
\mathrm{t} \text { programs } \\
\text { location }\end{array}$ & $21.4 \%$ & $78.6 \%$ & $100.0 \%$ \\
\hline & & \%within & $15.8 \%$ & $40.7 \%$ & $30.4 \%$ \\
\hline
\end{tabular}


International Journal of Business Management and Economic Review

Vol. 3, No. 04; 2020

ISSN: 2581-4664

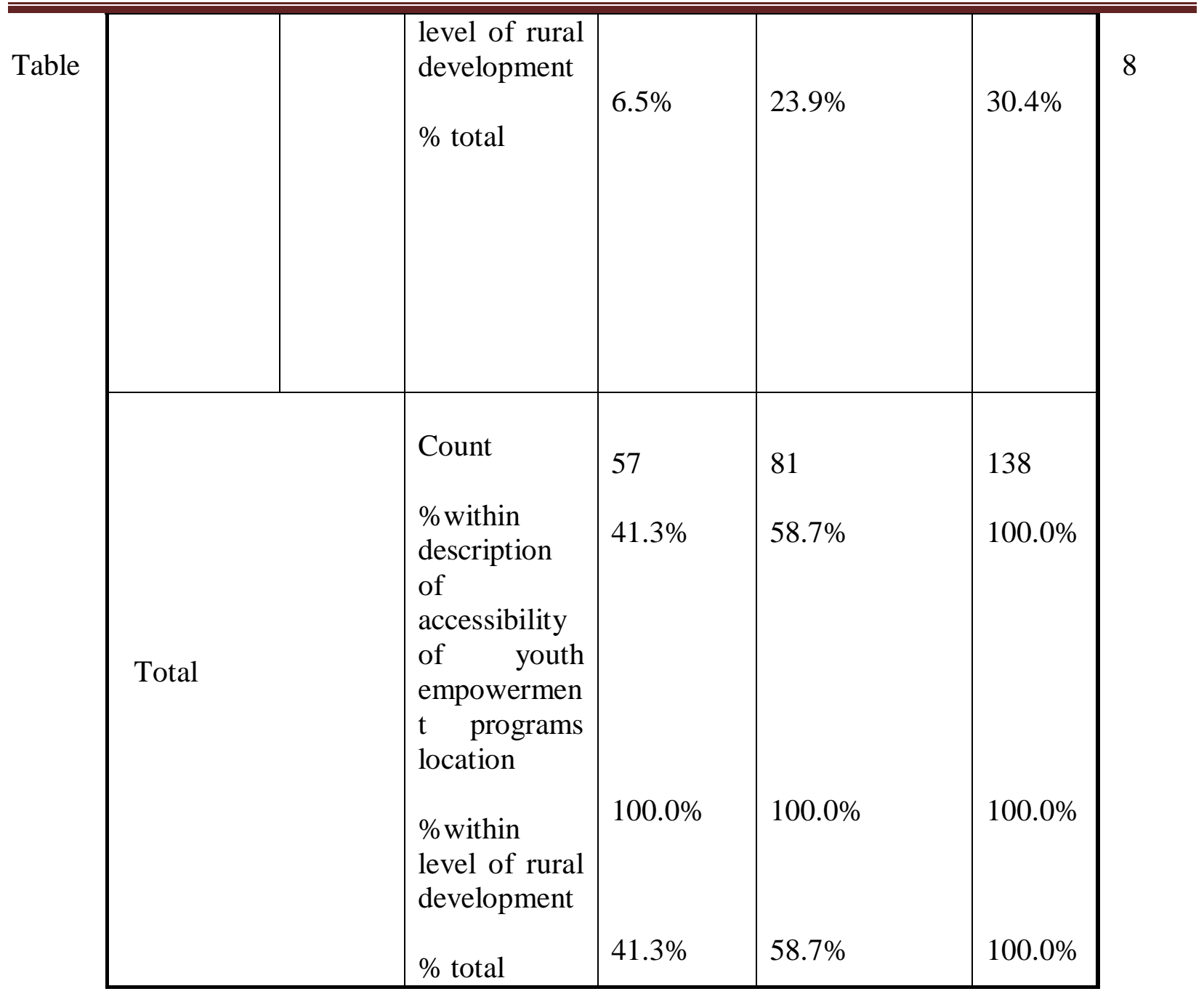

shows that $69.6 \%$ of the respondents indicated that they actively participated in youth empowerment programs while $30.4 \%$ passively participated in youth empowerment programs. Out of those who claimed that they actively participated, $50.0 \%$ indicated that their rural areas were developed while only $21.4 \%$ of those who passively participated claimed that their rural areas were developed. This implies rural development was affected by level of youth participation in the youth empowerment programs. This is further confirmed by the Chi square test results shown in Table 9.

Table 9: Chi-Square Tests (Level of Youth Participation)

\begin{tabular}{|llll|}
\hline & Value & df & Asymp. Sig. (2-sided) \\
\hline Pearson Chi-Square & $9.838(\mathrm{~b})$ & 1 & .002 \\
Continuity Correction(a) & 8.695 & 1 & .003 \\
Likelihood Ratio & 10.384 & 1 & .001 \\
Fisher's Exact Test & & & \\
\hline
\end{tabular}


Vol. 3, No. 04; 2020

ISSN: 2581-4664

\begin{tabular}{|l|llll|}
\hline \hline \multirow{2}{*}{ Linear-by-Linear Association } & 9.767 & 1 & .002 \\
\hline N of Valid Cases & $\mathbf{1 3 8}$ & & \\
\cline { 2 - 4 }
\end{tabular}

A Chi-square test was done on the frequencies to establish whether a statistically significant difference existed between respondents who actively participated in youth empowerment programs and those who passively participated in the programs. The computed Chi square value of 9.838 was significant with $\mathrm{p}=0.002<0.05$ at $5 \%$ level of significance and with 1 degree of freedom. This implies that there was a significant difference in rural development, between youth who actively participated in the youth empowerment programs and those who passively participated in the programs. This means that there was a significant relationship between level of youth participation in the empowerment programs and rural development.

4.4 Influence of Length of Youth Empowerment Programmes on Rural Development

This study set out to determine the influence of length of youth empowerment programmes on rural development in Rongo district. In this regard, the study sought to collect the respondents' views on how long projects took in the Kazi Kwa Vijana programmes and determine its effect on levels of rural development.

\subsubsection{Length of Time Involved in Empowerment Programmes}

Respondents were required to indicate the length of time they had been involved in the youth empowerment programs in Rongo District. Table 11 presents the findings.

\section{Table 11: Length of Time Involved in Empowerment Programmes}

\begin{tabular}{|c|c|c|}
\hline Time & Frequency & Percentage \\
\hline Under 1 Year & 59 & 42.8 \\
\hline 1 - 2 Years & 55 & 39.9 \\
\hline 3- 4 Years & 8 & 5.8 \\
\hline Above 4 Years & 16 & 11.6 \\
\hline Total & 138 & 100.0 \\
\hline
\end{tabular}

The majority (42.8\%) of the youth have been involved in empowerment programmes for less than one year in the Kazi Kwa Vijana projects, $39.9 \%$ of the youths have been involved in empowerment programmes for between one and two years, $5.8 \%$ for between three to four years and $11.6 \%$ for at least above four years. The main reason why the youth were active for less than one year as depicted by a high $42 \%$ indicator is that initially for the Kazi Kwa Vijana programme most of the youth could not access empowerment programmes as they were either exclusive to certain groups like church members or politically correct members only

\subsubsection{Relationship between Length of Youth Empowerment Programs and Rural Development}

The study sought to establish the relationship between the length of youth empowerment programs and rural development. Tables 11 and 12 show the findings. 
Vol. 3, No. 04; 2020

ISSN: 2581-4664

Table12: Cross tabulation of Length of Youth Empowerment Programs and Rural Development

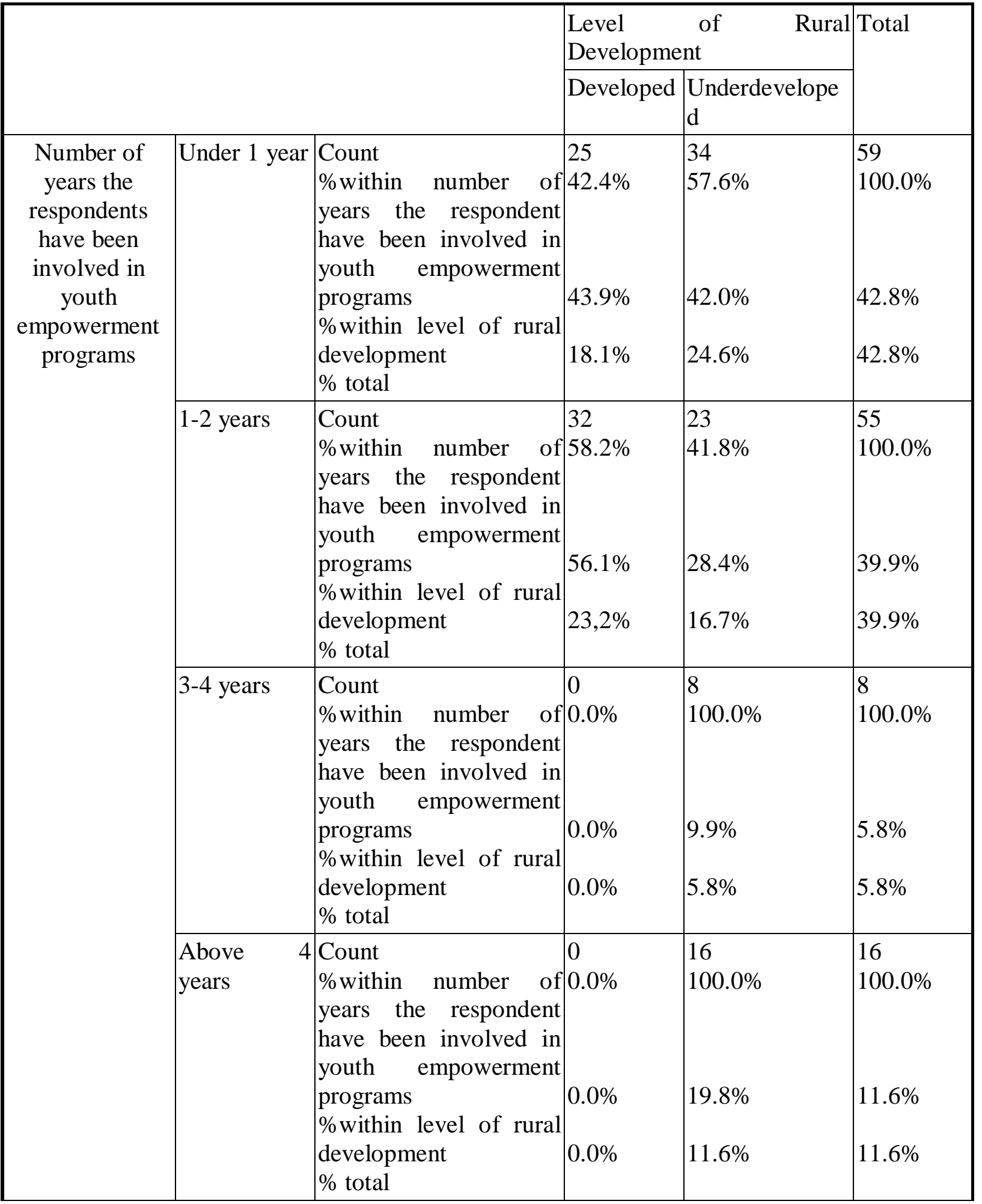




\section{International Journal of Business Management and Economic Review}

Vol. 3, No. 04; 2020

ISSN: 2581-4664

\begin{tabular}{|c|c|c|c|c|}
\hline Total & $\begin{array}{l}\text { Count } \\
\% \text { within number of } \\
\text { years the respondent } \\
\text { have been involved in } \\
\text { youth empowerment } \\
\text { programs } \\
\% \text { within level of rura } \\
\text { development } \\
\% \text { total }\end{array}$ & $\begin{array}{l}57 \\
41.3 \% \\
100.0 \% \\
41.3 \%\end{array}$ & $\begin{array}{l}81 \\
58.7 \% \\
100.0 \% \\
58.7 \%\end{array}$ & $\begin{array}{l}138 \\
100.0 \% \\
100.0 \% \\
100.0 \%\end{array}$ \\
\hline
\end{tabular}

Table 12 shows that $42.8 \%$ of the respondents indicated that they had been in the projects for below one year, $39.9 \%$ of the youths have been involved in empowerment programs for between one and two years, $5.8 \%$ for between three to four years and $11.6 \%$ for at least above four years. Out of those who claimed that they actively involved in the projects for less than one year, $42.4 \%$ indicated that their rural areas were developed while only $58.2 \%$ of those who had been involved in the programs for between one and two years claimed that their rural areas were developed. This implies rural development was affected by length of youth empowerment programs. This is further confirmed by the Chi square test results shown in table 13.

Table13: Chi-Square Tests (Length of Youth Empowerment Programmes)

\begin{tabular}{|l|l|l|l|}
\hline & Value & df & Asymp. Sig. (2-sided) \\
\hline Pearson Chi-Square & $23.379(\mathrm{a})$ & 3 & .000 \\
\hline Likelihood Ratio & 31.933 & 3 & .000 \\
\hline Linear-by-Linear Association & 9.384 & 1 & .002 \\
\hline N of Valid Cases & 138 & & \\
\hline
\end{tabular}

A Chi-square test was done on the frequencies to establish whether a statistically significant relationship existed between the length of empowerment program and rural development. The computed Chi square value of 23.379 was significant with $\mathrm{p}=0.000<0.05$ at $5 \%$ level of significance and with 3 degrees of freedom. This implies that there was a significant relationship between length of youth empowerment programs and rural development.

\section{CONCLUSION}

Based on the survey findings, the study made the following conclusions: The study concludes that Jua kali empowerment, environmental conservation programmes like tree planting and wetland area conservation, HIV/AIDS preventive programmes and financial empowerment through youth trust fund were practiced under the kazi kwa vijana program in Rongo district. In addition, social cultural programmes mainly in sporting activities like Sakata Boli by Safaricom and the ministry of youth and sports were also incorporated in the youth empowerment programmmes. The study also concluded that there was a significant relationship between the accessibility of the project and rural development. In addition, there is a significant relationship 


\section{International Journal of Business Management and Economic Review}

Vol. 3, No. 04; 2020

ISSN: 2581-4664

between the participation level of the youth in a project and development. Finally, the study concludes that there was a significant relationship between length of the programs and rural development. This implies that the Kazi Kwa Vijana programme had significantly influenced rural development in the study area.

\section{6 .RECOMMENDATIONS}

It is evident from this study that the Kazi Kwa Vijana programme has significantly influenced rural development in the study area. This calls for radical reforms in the programme to improve its efficiency, effectiveness and significance. In view of this, the study suggests the following recommendations:

Engaging the private sector in providing employment and training will improve the relevance of the training offered to youth and promote their future employability. Employers will need to be closely involved in the design of this activity and the targeting of youth participants. This expansion will hopefully result in increasing the employability of youth and will provide a basis for a possible nation-wide program charge of the overall coordination and monitoring.

Priority should be given to sub-projects that can be implemented rapidly using labor intensive techniques such as road maintenance sub-projects, small-scale water supply and sanitation subprojects, water harvesting sub-projects, afforestation sub-projects and waste collection. In addition to the KKV, the GoK continues to support the Youth Enterprise Development Fund (YEDF), established in 2006, providing youth with access to finance for self-employment activities and entrepreneurial skills development.

In order to improve its effectiveness and efficiency the programme should adopt the best practice operational features of public works program and together with the International Labour organization (ILO), provide important technical skills to improve the efficiency of the KKV. The support will strengthen the institutional arrangements for the program and further development of some operational features. This includes improved targeting mechanisms, optimization of employment content of sub-projects, the inclusion of services and effective monitoring and evaluation.

Given that employment programs, particularly labor intensive public work programs for youth, are likely to be needed in the medium term, there is need for the Government to master the management of these programs and to develop a design that allows for flexibility based on demand, with possible scaling-up and scaling-down as necessary. The support will ensure increased community participation in the sub-project selection which will lead to greater ownership and stronger sustainability.

In addition to improved operational features, the stakeholders should support the expansion of the KKV into youth training and internship with the private sector to ensure more sustainability for this support.

\section{AREA FOR FURTHER RESEARCH}

The current study was carried out in Rongo district found in Migori County. The KKV 


\section{International Journal of Business Management and Economic Review}

Vol. 3, No. 04; 2020

ISSN: 2581-4664

programme has been implemented in the entire Country. The study recommends a countrywide study to be conducted to compare the implementation of the program with that of other districts. The study also recommends further research on factors that influence the implementation of kazi kwa vijana programme.

\section{REFERENCES}

Akinyemi, V.J. (1990). Determinants of Citizen Participation Activities. University of Ibadan, Ibadan.

Blum, R.W. (2003). Positive Youth Development: A Strategy for Improving Health. Cambridge University Press; London.

Camino, Linda and Shepherd Zeldin (2002). "Making the Transition to Community Youth Development: Emerging Roles and Competencies for Youth-Serving Organizations and Youth Workers." Community Youth Development Anthology 2002, pp. 70-78. 2002.

Cargo, M., Grams, G.D., Ottoson, J. M., Ward, P., \& Green, L.W. (2003). Empowerment as Fostering Positive Youth Development and Citizenship." American Journal of Health Behavior, NewYork.

Chigunta, D.G. (2002) Appraisal of Factors Enhancing Youth Vocational Development. Journal of Social Education; Maputo.

Chinman, M. J., \& Linney, J.A. (1998). Toward A Model of Adolescent Empowerment: Theoretical and Empirical Evidence. Journal of Primary Prevention, 18, 393413.

Cook, P. J. (1991). The Technology of Personal Violence. Chicago University of Chicago Press, Chicago.

Freire, P. (1970).The Adult Literacy Process as Cultural Action for Freedom. Harvard Educational Review, Vol. 40 (2), 205-225.

Fraenkel, R.J. and Wallen,E.N. (2001). Educational Research: A Guide to the Process. NY: McGraw Hill.

Ginwright, Shawn and Taj J. (2003). "From Assets to Agents of Change: Social Justice, Organizing, and Youth Development." New Directions in Youth Development. 2003

GoK, (2006), Kenya National Youth Policy. Nairobi: Government Printer.

Israel G.D. (992). Determining Sample Size. Florida Cooperative Extension Service. University of Florida. PEOD-6. October. 1-5

Jacobs, D. Wertlieb, \& Lerner R.M. (2003), Handbook of Applied Developmental Science: Oxford, London

Jennings, L.B.,\&Green, J.L. (1999). Locating Democratizing and Transformative Practices within Classroom Discourse. Journal of Classroom Interaction, 34(2), i-iv. Jennings et al. 53.

Kim, S., Crutchfield, C., Williams, C., \& Hepler, N. (1998). Toward A New Paradigm in Substance Abuse and Other Problem Behavior Prevention for Youth: YouDevelopment and Empowerment Approach. Journal of Drug Education.

Mangione,T.W. (1995). Mail Surveys Improving the Quality. Applied Socia Research Methods Series, International Educational and Professional Publication, Vol.40. Sage Publications Inc. Thousand Oaks London New Delhi. 


\section{International Journal of Business Management and Economic Review}

Vol. 3, No. 04; 2020

ISSN: 2581-4664

Messner, S. and Tardiff, K. (1986). Economic Inequality and Levels of Homicide: An Analysis of Urban Neighbourhoods. Criminology, 24:297-318

Minkler and N. Wallerstein (Eds.), Community-Based Participatory Research for Health; San Francisco: Jossey-Bass.

Ojikutu, A.A.(1998) Community Participation in Development of Secondary School Building in Irele Local Government Area, University of Ibadan, Ibadan.

Oladele, O.R. (2003) Citizen Participation in Community Development. A case Study of Afijo Local Government Area. University of Ibadan, Ibadan.

Pinderhughes, E. (1995). Empowering Diverse Populations: Family Practices in the $21^{\text {st }}$ Century. Families in Society, 76(3), 131-140.

Rappaport, J. (1984). Studies in Empowerment: Introduction to the Issue. Prevention in Human Services, 3, 1-7.

Rappaport, J. (1987). Terms of Empowerment/Exemplars of Prevention: Toward A Theory for Community Psychology. American Journal of Community Psychology.

Ray, M. A. (1992). Critical Theory as A Framework to Enhance Nursing Science. Nursing Science Quarterly, 5(3), 98-101.

Reiss, A.J. Jr. (1988). Co-Offending and Criminal Careers. University of Chicago Press, Chicago.

Rissel, C. (1994). Empowerment-The Holy Grail of Health Promotion. Health Promotion International, 9(1), 39-47.

Rocha, E.M. (1997). A Ladder of Empowerment. Journal of the American Planning Association, 17, 31-44.

Roth, J., Brooks-Gunn, J., Murray, L., \& Foster, W. (1998). Promoting Healthy Adolescents: Synthesis of Youth Development Program Evaluations. Journal of Research

Sampson, R. and Lauritsen, J. (1993). Violent Victimization and Offending Individual Situational and Community Level Risk Factors. National Academy of Sciences. Washington DC.

Schueman, L. and Kobrin, S.(1986). Community Careers in Crime. Communities and Crime. Crime and Justice: Chicago Press; Chicago.

Small, S., \& Memmo, M. (2004). Contemporary Models of Youth Development and Problem

Wallerstein, N., Sanchez-Merki, V.,\& Verlade, L. (2005). Freirian Praxis in Health Education and Community Organizing: A Case Study of an Adolescent Prevention Program. Prentice Hall. London.

World Bank (1994) Distribution and Growth: Compliments not Compromise. Policy Research Bulletin; New York.

WHO (2007). Youth and Development in the Contemporary World; Harvard; New York

Zimmerman, M. A. (1995). Psychological Empowerment: Issues and Illustrations. American Journal of Community Psychology, 23(5), 581-599.

Zimmerman, M. A. (2000). Empowerment Theory: Psychological, Organizational, and Community Levels of Analysis. In J. R. E. Seidmann (Ed.), Handbook of Community Psychology. New York: Kluwer Academic/Plenum.

Zimmerman, M. A., \& Rappaport, J. (1988). Citizen Participation, Perceived Control, and Psychological Empowerment. American Journal of Community Psychology, 